\section{Reprodutibilidade de um questionário para avaliação de conhecimentos, percepções e práticas em segurança sanitária alimentar de portadores de HIV/AIDS ambulatoriais}

\author{
Reliability of a questionnaire to assess food safety \\ knowledge, perceptions, and practices among \\ outpatients with human immunodeficiency virus
}

\author{
${ }^{1}$ Hospital Escola \\ São Francisco de Assis, \\ Universidade Federal do \\ Rio de Janeiro, Rio de Janeiro, \\ Brasil. \\ 2 Instituto Nacional de \\ Controle de Qualidade em \\ Saúde, Fundação Oswaldo \\ Cruz, Rio de Janeiro, Brasil. \\ 3 Escola Nacional de Saúde \\ Pública Sergio Arouca, \\ Fundação Oswaldo Cruz, \\ Rio de Janeiro, Brasil. \\ Correspondência \\ L. H. M. Leite \\ Hospital Escola São Francisco \\ de Assis, Universidade \\ Federal do Rio de Janeiro. \\ Av. Presidente Vargas 2863. \\ Rio de Janeiro, RJ 20210-031, \\ Brasil. \\ luisamaia@uol.com.br
}

\begin{abstract}
HIV-positive patients are at increased risk of acquiring infections, particularly those related to water and food. The risk could be reduced by educational interventions in the clinical setting related to food safety for the prevention of food-borne diseases. The current study aimed to analyze food safety knowledge, perceptions, and practices among HIV-positive outpatients. A questionnaire was organized with five behavioral areas (cross contamination; personal hygiene; household hygiene; temperature control; and control of unsafe foods). The test-retest procedure demonstrated the questionnaire's reliability. Kappa values varied among the questions: high for $84.6 \%$ (33); moderate for $12.8 \%$ (5); and low for $2.5 \%$ (1). Based on the results, the instrument showed good reliability for most of the questions and can be used for surveys on food safety in HIV-positive outpatients.
\end{abstract}

Food Security; Acquired Immunodeficiency Syndrome; Nutrition; Questionnaires
Luísa Helena Maia Leite 1,2

William Waissmann 2,3

Alessandra Bento Veggi 3

\section{Introdução}

As doenças veiculadas por água e alimentos representam um importante problema de saúde pública no mundo ${ }^{1}$. Na atualidade recomenda-se, como uma das estratégias preventivas no campo da segurança alimentar, a proteção dos "grupos de risco", tais como: idosos, gestantes e imunodeprimidos 2 . O conceito de segurança alimentar compreende duas acepções. No contexto sanitário, pode ser entendida como "o conjunto de propriedades dos alimentos que resultam, ao mesmo tempo, de sua inocuidade (ausência de riscos à saúde pública); de sua integridade (ausência de defeitos e alterações); e de sua autenticidade (ausência de fraudes ou falsificações)" 3 (p. 243). Por outro lado, no contexto nutricional, relaciona-se com o acesso de todas as pessoas, por todo o tempo, a quantidades suficientes de alimentos para uma vida ativa e saudável 4 .

Dentre os "grupos de risco", os portadores de HIV/AIDS merecem atenção especial, tendo em vista que as infecções intestinais, incluindo aquelas veiculadas por água e alimentos, têm sido problema comum neste grupo, atingindo cerca de $60-90 \%$ dos pacientes 5,6 nos anos que antecederam a terapia HAART (Highly Active Antiretroviral Therapy), permanecendo como causa significante de morbidade em indivíduos HIV positivos, mesmo após a era HAART 7.

Evidências epidemiológicas sugerem que significativa parte dos casos de doenças veicu- 
ladas por água e alimentos esteja relacionada com falhas de segurança sanitária alimentar no preparo doméstico dos alimentos ${ }^{8}$. Medeiros et al. 9 destacam que as principais falhas na manipulação de alimentos, no ambiente domiciliar, se concentram em torno de cinco práticas inseguras. São elas: contaminação cruzada; falhas na higiene pessoal e ambiental; falhas no controle de temperaturas e consumo de alimentos de risco. Neste sentido, alguns estudos têm avaliado o nível de conhecimentos dos consumidores sobre as doenças veiculadas por água e alimentos e suas conseqüências, demonstrando que a população, de forma geral, não possui conhecimentos suficientes para se proteger destas doenças 10,11. Em relação aos portadores de HIV/AIDS, a literatura aponta a escassez de instrumentos elaborados para avaliar a adoção de práticas de segurança sanitária alimentar, consideradas de importância especial para imunodeprimidos e também que tenham sido validados 12 .

Este estudo teve como objetivos desenvolver um questionário para avaliar os conhecimentos, as percepções e práticas em segurança alimentar de portadores de HIV/AIDS ambulatoriais e medir o nível de reprodutibilidade do instrumento, visando o planejamento de estratégias de educação em segurança alimentar em um estudo a ser conduzido posteriormente.

Participaram do estudo quarenta portadores de HIV/AIDS ambulatoriais, adultos, em tratamento regular, acompanhados no ambulatório de um hospital universitário, na cidade do Rio de Janeiro, Brasil. Foi definida uma amostra de conveniência, considerando o valor aproximado de $10 \%$ do universo de portadores de HIV/AIDS ( $\mathrm{n}=445$ ) que deveriam ser incluídos no estudo posterior. A maioria era do sexo masculino (65\%), com idade entre 26-59 anos (90\%), e com grau de instrução variando de nível fundamental a médio (90\%).

Para construir o questionário, optou-se por não realizar a tradução integral dos instrumentos disponíveis na literatura devido às diferenças de hábitos alimentares e aos padrões de consumo de alimentos de risco, muitos dos quais não se reproduzem no Brasil. Foram adotadas cinco dimensões em segurança sanitária alimentar: prevenção da contaminação cruzada; higiene pessoal, ambiental; controle de temperaturas de conservação e prevenção do consumo de alimentos de risco ${ }^{9}$. As questões foram elaboradas tendo como base publicações da literatura científica voltadas para a coleta de informações da população geral sobre práticas de manipulação dos alimentos, dentro das cinco dimensões citadas. Questões de interesse foram selecionadas e adaptadas à realidade sócio-cultural brasileira $13,14,15,16$. De forma complementar foram incorporadas questões sobre práticas de higiene e segurança sanitária alimentar relacionados com os enteropatógenos de alta gravidade para os imunodeprimidos, bem como as práticas de segurança alimentar mais eficientes para prevenilos 12. O instrumento foi submetido à avaliação crítica de cinco nutricionistas especialistas em segurança sanitária alimentar (quatro professores universitários e um profissional de inspeção municipal). Todas as modificações sugeridas foram adotadas. A coleta de dados foi feita por um único pesquisador, utilizando-se o procedimento de teste e re-teste, com um intervalo de sete dias entre a primeira e a segunda entrevista. Para estimar o nível de concordância optou-se por analisar o coeficiente kappa simples, tendo em vista que o formato de respostas para todas as perguntas incluiu a opção de resposta "não sei", inviabilizando o cálculo do kappa ponderado. Os cálculos foram realizados segundo Fleiss et al. 17 . Foram adotados os pontos de corte propostos por Landis \& Koch 18: quase perfeita $(>0,80)$; forte ou substancial $(0,61-0,80)$; moderada $(0,41-0,60)$; regular $(0,21-0,40)$; fraca $(0,01-0,20)$ e pobre $(0,00)$. Utilizou-se o programa Epi Info 2000 (Centers for Disease Control and Prevention, Atlanta, Estados Unidos) para a entrada dos dados e o programa Stata v. 7.0 (Stata Corporation, College Station, Estados Unidos) para análise dos resultados. O estudo foi conduzido após a aprovação do comitê de ética em pesquisa da unidade, segundo a Resolução $n^{\circ}$. 196/96, para pesquisa em seres humanos.

A Tabela 1 mostra que, de forma geral, o estudo de reprodutibilidade deste questionário revelou um nível de concordância considerado substancial $(k>0,61)$ para $84,6 \%$ das questões testadas, sugerindo uma boa estabilidade, similar a resultados de outros inquéritos anteriores $19,20,21$.

Cinco questões apresentaram um nível de reprodutibilidade abaixo de $0,60(\mathrm{k}=0,40$ a 0,60$)$. Duas delas situavam-se no bloco de questões sobre a prevenção da contaminação cruzada. Uma delas relacionava-se ao hábito de usar esponjas para higienizar superfícies após o contato com carnes cruas $(k=0,57)$. E a outra questão era sobre higiene das mãos após manipular carnes cruas $(k=0,43)$. As outras três perguntas situavam-se nos blocos de questões sobre controle de temperaturas e controle de alimentos de risco. Uma delas referia-se à prática de deixar carnes à temperatura ambiente por mais de duas horas $(k=0,55)$. Outra questão era sobre a prática de conferir as condições das cascas de ovos antes da compra $(k=0,40)$. E a última questão era sobre o 
Seções e níveis de reprodutibilidade do questionário para avaliar conhecimentos, percepções e práticas em segurança sanitária alimentar de portadores de HIV/AIDS.

Seções do questionário

Valores kappa Classificação

IC95\%

Conhecimentos sobre doenças transmitidas por alimentos

Na sua opinião, os alimentos que possuem boa aparência e cheiro agradável

podem causar doenças? [Sim/Não]

Quais são os sintomas mais comuns das doenças veiculadas por água e alimentos que o

Sr.(a). conhece? [Febre e coceira no corpo/Vômitos e diarréia/Dor de garganta e febre]

Para o Sr.(a). o risco de contrair doenças veiculadas por água e alimentos ao consumir

alimentos preparados em sua casa é? [Alto/Moderado/Baixo/Nenhum]

Para o Sr.(a). o risco de contrair doenças veiculadas por água e alimentos ao consumir alimentos

preparados fora de sua casa é? [Alto/Moderado/Baixo/Nenhum]

Nas consultas ambulatoriais, para o tratamento de HIV/AIDS o Sr.(a). recebeu alguma

informação sobre a prevenção de doenças transmitidas por alimentos? [Sim/Não]

Após a confirmação do vírus HIV, o Sr.(a). deixou de comer algum alimento por considerar

o seu consumo perigoso? [Sim/Não]

Em algum momento do seu tratamento o Sr.(a). foi atendido por um nutricionista? [Sim/Não]

Conhecimentos, percepções e práticas sobre contaminação cruzada

Imagine que o Sr.(a). precise usar uma tábua de corte (ou similar) para cortar carne crua

(frango, peixe etc.) e depois vá cortar outro alimento, cru ou cozido, o que costuma fazer?

[Lavo a tábua com água/Lavo a tábua com água e sabão/Lavo a tábua com água quente

e sabão/Uso outra tábua ou outra superfície/Não sei]

Com que freqüência se usa a mesma esponja para lavar tábuas de carne e copos, pratos etc.

em sua casa? [Sempre se usa a mesma esponja/Algumas vezes se usa a mesma esponja/

Usam-se esponjas diferentes/Não se usam esponjas/Não sei]

Durante o preparo dos alimentos, o Sr.(a). lava as mãos imediatamente após manipular carne,

frango ou peixes crus? [Sempre lavo as mãos com água e sabão/Algumas vezes lavo as mãos

com água e sabão/Nunca lavo as mãos com água e sabão/Não manipulo carnes cruas/Não sei]

Conhecimentos, percepções e práticas sobre higiene pessoal/ambiental e de alimentos

O Sr.(a). lava as mãos com água e sabão antes de preparar alimentos, inclusive lanches?

[Sempre lavo as mãos com água e sabão/Algumas vezes lavo as mãos com água e sabão/

Nunca lavo as mãos com água e sabão/Lavo só com água/Não sei]

Ao preparar saladas cruas, em sua casa, como são higienizadas as folhas? [São lavadas somente em água corrente/São lavadas em água corrente e colocadas de molho em vinagre/São lavadas em

0,71

Forte

$0,47-0,95$

0,63

Forte

$0,07-1,20$

0,66

Forte

$0,45-0,87$

0,63

Forte

$0,37-0,88$

0,90

Forte

$0,65-1,16$

0,93

Forte

0,78-1,07

0,86

Forte

0,65-1,07

0,67

Forte

$0,44-0,89$

água corrente e postas de molho em solução de água sanitária/Não preparo saladas cruas/Não sei] O Sr.(a). possui animais domésticos (cão, gato etc.)? [Sim/Não]

A água consumida em casa é filtrada? [Sim/Não]

Costuma ferver a água antes de consumir? [Sempre fervo/Algumas vezes fervo/Nunca fervo/Não sei]

0,57

Moderada

$0,40-0,74$

Moderada

$0,12-0,74$

Conhecimentos, percepções e práticas sobre controle de temperaturas

Durante as compras dos alimentos, em que momento carnes, peixes e frango são colocados no

carrinho ou cesta de compras? [No início das compras/No meio das compras/No final das compras/

Não compra carnes/Não sei]

Em média quanto tempo leva do local de compras até sua residência? [Menos de 30 minutos/

Entre 30 a 60 minutos/Entre 1 e 2 horas/Mais de 2 horas/Não sei]

O Sr.(a). costuma deixar carne/frango/peixe crus fora da geladeira mais de 2 horas? [Sempre deixo/

Algumas vezes deixo/Nunca deixo/Não sei]

Depois de prontos o Sr.(a). costuma deixar os alimentos à temperatura ambiente por quanto tempo, aproximadamente? [Menos de 2 horas/Entre 2 e 6 horas/Mais de 6 horas/

Não deixo alimentos à temperatura ambiente/Não sei]

Como é feito o descongelamento de carne/frango/peixes em sua casa? [Descongelo embaixo da torneira/Descongelo em um recipiente com água, fora da geladeira/Descongelo na geladeira/ Descongelo no forno microondas/Não sei]

(continua) 
Tabela 1 (continuação)

Conhecimentos, percepções e práticas sobre controle de alimentos de risco

Quando compra alimentos, o Sr.(a). costuma conferir as informações de rotulagem?

[Sempre confiro/Algumas vezes confiro/Nunca confiro, observo apenas o preço/

Confiro apenas a data de validade/Não sei]

Quando o Sr.(a). compra ovos observa o aspecto e as condições da casca?

[Sempre confiro/Algumas vezes confiro/Nunca confiro, observo apenas o preço/

Não compro ovos/Não sei]

Nos últimos 6 meses consumiu carnes vendidas por ambulantes? [Sim/Não]

Nos últimos 6 meses consumiu leite sem tratamento industrial? [Sim/Não]

Nos últimos 6 meses consumiu carnes cruas ou "mal passadas"? [Sim/Não]

Nos últimos 6 meses consumiu ovos crus ou com gema mal cozida? [Sim/Não]

Nos últimos 6 meses consumiu peixes crus ou mal cozidos? [Sim/Não]

Nos últimos 6 meses consumiu água de poço, fonte ou mina? [Sim/Não]

$\begin{array}{ccc}0,88 & \text { Forte } & 0,58-1,16 \\ 1,0 & \text { Perfeita } & - \\ 0,83 & \text { Forte } & 0,65-1,0 \\ 0,76 & \text { Forte } & 0,53-0,99 \\ 0,53 & \text { Moderada } & -0,2-1,0 \\ 1,0 & \text { Perfeita } & -\end{array}$

consumo de pescados crus ou mal cozidos nos últimos seis meses $(k=0,53)$.

Acreditamos que a reprodutibilidade de algumas questões pode ter sido influenciada pelas características do grupo estudado, tendo em vista que a maioria (65\%) era do gênero masculino e 90\% tinham nível de escolaridade variando de médio a fundamental. Outros inquéritos anteriores já haviam demonstrado freqüência maior de falhas de segurança alimentar, como a não observância de informações de rotulagem, conferência dos aspectos sensoriais dos alimentos, consumo dos alimentos de alto risco e falhas nos procedimentos de descongelamento, para grupos de homens com menores graus de instrução 22,23 .

Uma única questão apresentou nível de reprodutibilidade abaixo de 0,40. Esta relacionavase ao hábito de lavar as mãos com água e sabão antes de preparar os alimentos, inclusive lanches $(k=0,32)$. Nós acreditamos que o formato das respostas, que incluía uma opção "lava as mãos só com água" tenha ocasionado dúvidas em relação a opção de resposta "algumas vezes lava as mãos com água e sabão”. Pela relevância, a questão foi reformulada, excluindo-se a opção de resposta "lava as mãos só com água" e a mesma foi mantida no estudo.

Outro fator reconhecido por influenciar o nível de reprodutibilidade em estudos de teste e re-teste é o intervalo de tempo decorrido entre a primeira e a segunda entrevista, sendo recomendado um intervalo inferior a 15 dias 24 , o que foi observado neste estudo.

O estudo de reprodutibilidade deste questionário mostrou um nível de concordância forte ou substancial para a maioria das questões, sugerindo que o mesmo possui uma estabilidade satisfatória. São necessários estudos futuros que contemplem outros aspectos da confiabilidade e validade visando o aprimoramento deste instrumento para utilização em outras populações. 
Resumo

Portadores de HIVIAIDS são vulneráveis a muitos tipos de infecções, incluindo aquelas veiculadas por água e alimentos. O alto risco às infecções gastrintestinais poderia ser minimizado através do aconselhamento dietético, no ambiente das unidades de saúde ambulatoriais, visando à adoção de práticas de segurança sanitária alimentar. A pesquisa realizada teve como objetivo, dentre outros, avaliar os conhecimentos, as percepções e práticas em segurança alimentar de portadores de HIVIAIDS ambulatoriais. Para tal, elaborou-se questionário, a partir de cinco áreas temáticas (prevenção da contaminação cruzada; higiene pessoal e ambiental; controle de temperaturas; e consumo de alimentos de risco). O que se apresenta é o estudo de reprodutibilidade desse instrumento, para o qual foi utilizado o procedimento de teste e re-teste. Os resultados deste estudo mostraram que os valores kappa oscilaram de forte para 84,6\% (33), moderado para $12,8 \%$ (5), a discreto para 2,5\% (1) das questões testadas. Nossos resultados sugerem que o instrumento apresenta um bom nível de reprodutibilidade sendo uma boa opção para o levantamento de informações sobre segurança alimentar de pacientes portadores de HIVIAIDS.

Segurança Alimentar e Nutricional; Síndrome de Imunodeficiência Adquirida; Nutrição; Questionários

\section{Colaboradores}

L. H. M. Leite realizou a revisão bibliográfica, construção do instrumento, trabalho de campo e análise e discussão dos resultados. A. B. Veggi colaborou na análise e discussão dos resultados. W. Waissmann coordenou a etapa de construção do instrumento e colaborou na análise e discussão dos resultados. Todos os autores participaram da elaboração da versão final do artigo.

\section{Agradecimentos}

Ao Centro Colaborador em Vigilância Sanitária, Convênio Escola Nacional de Saúde Pública/Agência Nacional de Vigilância Sanitária pelo financiamento da pesquisa.

\section{Referências}

1. Kosec M, Bern C, Guerrant RL. The global burden of diarrhoeal disease, as estimated from studies published between 1992-2000. Bull World Health Organ 2003; 81:197-204.

2. Gerba CP, Rose JB, Haas CN. Sensitive populations: who is the greatest risk? Int J Food Microbiol 1996; 30:113-23.

3. Cosson C, Bolnot FH, Tronchon P. "Sécurité alimentaire" en milieu hospitalier: de la logique de crise à la logique du progrès. Nutrition Clinique et Métabolisme 2003; 17:242-51.

4. American Dietetic Association. Position of the American Dietetic Association: domestic food and nutrition security. J Am Diet Assoc 2002; 102:18407.

5. Angulo F, Swerdlow DL. Bacterial enteric infections in persons infected with human immunodeficiency virus. Clin Infec Dis 1995; 21 Suppl 1:84-93.
6. Altekruse S, Hyman F, Klondz K, Timbo B, Tollefson L. Foodborne bacterial infections in individuals with the human immunodeficiency virus. South Med J 1998; 87:169-73.

7. Call SA, Heudbert G, Saag M, Wilcox CM. The changing etiology of chronic diarrhea in HIV-infected patients with CD4 cell counts less than 200 cells/mm³. Am J Gastroenterol 2000; 95:3142-6.

8. Redmond EC, Griffith CJ. Consumer food handling in the house: a review of food safety studies. J Food Prot 2003; 66:130-61.

9. Medeiros LC, Hillers VN, Kendall PA, Mason A. Food safety education: what should we be teaching to consumers? J Nutr Educ 2001; 33:108-13.

10. Angellilo IF, Foresta MR, Scozzafava C, Pavia M. Consumers and foodborne diseases: knowledge, attitudes and reported behavior in one region of Italy. Int J Food Microbiol 2001; 64:161-6. 
11. Meer RR, Misner SL. Food safety knowledge and behavioral of expanded food and nutrition education program participants in Arizona. J Food Prot 2000; 63:1725-31.

12. Kendall P, Medeiros L, Hillers VN, Cheng G, Di Mascola S. Food handling behavioral of special importance for pregnant women, infants and young children, the elderly and immune-compromised people. J Am Diet Assoc 2003; 103:1646-9.

13. Jay LS, Comar D, Govenlock LD. A national Australian food safety telephone survey. J Food Prot 1999; 62:921-8.

14. Yang S, Leff MG, McTague D, Hovarth KA, JacksonThompson J, Murayi T, et al. Multi-state surveillance for food-handling, preparation, and consumption behaviors associated with foodborne diseases; 1995 and 1996 BRFSS food-safety questions. MMWR Morb Mortal Wkly Rep 1998; 47: 33-57.

15. Worsfold D, Griffith CJ. A generic model for evaluating consumer food safety behaviour. Food Control 1995; 6:357-63.

16. Heathcock R, McLauchlin J, Newton LH, Soltanpoor N, Coker R, Bignardi G, et al. Survey of food safety awareness among HIV-positive individuals. AIDS Care 1998; 10:237-41.

17. Fleiss JL, Levin B, Paik MC. Statistical methods for rates and proportions. New Jersey: Wiley Interscience; 2003.
18. Landis LR, Koch GG. The measurement of observer agreement for categorical data. Biometrics 1977; 33:159-74.

19. Medeiros LC, Hillers VN, Chen G, Bergman V, Kendall P, Schoeder M. Design and development of food safety and attitude scales for consumer food safety education. J Am Diet Assoc 2004; 104: 1671-7.

20. Westaway MS, Viljoen E. Health and hygiene, attitudes and behaviour. Health Place 2000; 6:25-32.

21. Haapala I, Probart C. Food safety knowledge, perceptions and behaviors among middle school students. J Nutr Educ Behav 2004; 36:71-6.

22. Mitakakis TZ, Sinclair MI, Fairley CK, Lightbody PK, Leder K, Hellard ME. Food safety in family homes in Melbourne, Australia. J Food Prot 2004; 67:818-22.

23. Shiferaw B, Yang S, Cielask P, Vugia D, Marcus R, Koehler J, et al. Prevalence of high-risk food consumption and food handling practices among adults: A multi-state survey, 1996 to 1997. J Food Prot 2000, 63:1538-43.

24. Salvo VLMA, Gimeno SGA. Reprodutibilidade e validade do questionário de freqüência de consumo de alimentos. Rev Saúde Pública 2002; 36:505-12.

Recebido em 20/Jun/2005

Versão final reapresentada em 23/Nov/2006 Aprovado em 04/Jan/2007 